\title{
Participation-reputation based incentive game model (PRIGM) for trustworthy fisheries information collection and dissemination framework
}

\author{
Sadiki Lameck Kusyama $^{{ }^{*}}$, Dina Machuve ${ }^{2}$, Michael Kisangiri ${ }^{3}$ and Abuswaid Mfanga ${ }^{4}$ \\ Scholar, Nelson Mandela Institution of Science and Technology, School of Computational and Communication \\ Sciences and Engineering, Tanzania ${ }^{1}$ \\ Lecturer, Nelson Mandela Institution of Science and Technology, School of Computational and Communication \\ Sciences and Engineering, Tanzania ${ }^{2}$ \\ Senior Lecturer, Nelson Mandela Institution of Science and Technology, School of Computational and \\ Communication Sciences and Engineering, Tanzania ${ }^{3}$ \\ Lecturer, Moshi Co-operative University, Department of Information and Communication Technology, Tanzania ${ }^{4}$
}

Received: 01-August-2020; Revised: 25-September-2020; Accepted: 28-September-2020

(C)2020 Sadiki Lameck Kusyama et al. This is an open access article distributed under the Creative Commons Attribution (CC BY) License, which permits unrestricted use, distribution, and reproduction in any medium, provided the original work is properly cited.

\begin{abstract}
The fisheries and aquaculture sectors worldwide use Information and communication technologies (ICT) to collect and disseminate fisheries information. Currently, the African member state is significantly strengthening the use of ICT systems in data collection and dissemination to ensure timely access and accurate fisheries information. Fisheries stakeholders are obliged to submit and retrieve information honestly as well as provide feedback voluntarily. We conducted ancient literature reviews to discover worldwide and indigenous struggles towards developing and implementing fisheries data collection and dissemination systems. Existing worldwide and indigenous innovation systems bases on voluntary user participation and lacks effective incentive mechanisms. However, due to dishonest human behavior, such a promise is impractical. Without an efficient mechanism to incentivize fisheries stakeholders, it would not be easy to achieve the required system adoption and performance. This paper proposed an evolutionary participationreputation incentive game-based mechanism (PRIGM) to motivate fisheries stakeholders to contribute accurate information, retrieve information, and return honest feedback to the system. Our proposed model adopts stakeholder participation and reputation as merit to incentivize the honest stakeholder and punish the dishonest one. Our proposed PRIGIM model modeled the stakeholder's participation as an evolutionary game and coded the model using the python programming language. We simulated the model in five cases using randomly generated data, each with four-game rounds plays, using a different number of stakeholder participants in each case. Lastly, we used a bar chart graph to evaluate stakeholder's honest and dishonest behavior. The simulation results show that no matter the population of stakeholders, many stakeholders choose a dishonest strategy at the beginning of the game; after several game rounds, most stakeholders will be motivated to choose a simple strategy. Our simulation results proved that PRIGIM effectively motivates stakeholders to use the system, contribute accurate information, and return truthful feedback.
\end{abstract}

\section{Keywords}

Participation score, Reputation score, Incentive, Honest, Dishonest, Evolutionary game.

\section{Introduction}

Scholars worldwide have reported the importance of information communication technology (ICT) in fisheries sector development. Previous research discovered that ICT usage could enhance the fishermen's productivity by providing opportunities for the anglers to get fair and competitive market price of their catch [1].

\footnotetext{
*Author for correspondence
}

Cultivating the capability to improve access to information through enhanced information pursuing behavior-using ICT enriches local fish production [2].

Correct information raises decision-making, improves efficiency, and delivers a competitive advantage [3]. Information is an authority when adequately attained, transferred, and consumed, can help to escalate the fish production rate amongst participants in fishing groups [4]. 
Additionally, angler's absence of access to information and knowledge hinders them from improving their fisheries activity [5]. Underprivileged availability of information and expertise among anglers reduces the fish production rate [6]. If the use of ICTs in retrieving, sharing fisheries information and knowledge is encouraged, the fish production rate can increase.

ICTs can transmit information and knowledge to fisheries stakeholder groups and convey all the required information about the different fishing practices and future activities [7]. Furthermore, [8] reported that the African member state requires a significant strengthening of ICT systems. The enhancement can be achieved by employing ICT in data collection and dissemination to ensure access to timely and accurate fisheries information.

The report further stated that, due to the highly dispersed nature of the fisheries subsector, data collection and dissemination remain a big challenge. Worldwide scholars have proposed several innovations to address data collection and dissemination challenges. For example, South Africa developed the ABALOBI initiative from open source software to monitor, trace, and collect small-scale fisher's data [9]. Enhanced fish market information service Kenya (EFMIS-Ke) is a virtual marketplace application aiming to enable anglers to access market information and moderate poverty by making prices more transparent [10]. In the Solomon Islands, HapiFish, a mobile phone application developed to enable easy and efficient access for market and biological data [10]. Esoko, an ICT platform developed in Ghana to facilitate data collection, market information, and payments designed explicitly for crop farmers, can be customized for fishers [11].

However, participating in such crowdsourcing nature system usually have a cost for individual users. Such charges may be the user's resources consumption like computing power, battery, airtime, internet bundle. On the other side, the system may require the submission of some of the users' sensitive private information, which may cause privacy leakage for participating users. For example, fishers, by uploading the daily catch, reveal their regular earnings. By submitting a landing site, fishers usually disclose information about their locations. However, without reasonable incentives that compensate participating costs, users will be reluctant to use such systems. Most of the existing innovation systems bases on voluntary user participation and lacks effective incentive mechanisms.

This study reviewed and analyzed various research papers about fisheries data collection and dissemination systems and incentive mechanism development. It included national, regional, and international efforts towards fisheries data collection and dissemination systems. This study's objective was to examine the weakness, strengths, and challenges facing fisheries data collection and dissemination systems and incentive mechanisms imposed to solve dishonest behaviors among stakeholders. Based on the identified weaknesses, strengths, and challenges, we proposed PRIGM, which implements a participation-reputation-based incentive game to motivate the system user to use the system, contribute accurate information, and upload truthful feedback. In PRIGM, participation and reputation are used as criteria to incentivize the honest users and punish the dishonest ones. The mechanism provides incentives to the legitimate user as a discount in the license and other service fees.

\section{Related work}

Crowdsourcing practice can solve the enterprise properties related to man, machine, money, method, material, and marketing [12]. As discussed earlier, users of crowdsourcing nature systems will be unwilling to use the system, contribute information, and provide feedback if not adequately motivated to do so through an effective incentive scheme. Researchers have devoted themselves to propose several incentive mechanisms to encourage crowdsourcing system users to eradicate such a dilemma. Researchers [13] studied different incentive approaches that urged users to participate in crowdsourcing nature applications and categorized them into entertainment, service, and money. Another research [14] proposed a three-incentive mechanism, namely, threshold-based auction (TBA), the truthful online incentive (TOIM), and truthful online incentive non-zero arrival-departure (TOIM-AD). The TBA mechanism aimed to maximize user's utility while TOIM and TOIM-AD targeted trade-off utility maximization and truthfulness.

Furthermore, a truthful and budget feasible mechanism focused on the strict budget constraint was proposed [15]. Lastly, [16] proposed an incentive mechanism to encourage user participation based on the quality-driven auction. In their proposed incentive mechanism, they accounted for data quality as a parameter to incentivize system participants. 
However, these researchers did not consider both providers and requesters' participation and honesty in their proposed mechanism.

\section{PRIGM model overview}

The general PRIGM model (shown in Figure 1) consists of information collection and dissemination system server and fisheries stakeholders, categorized as information providers and information users, respectively, at any time. The information user can upload information via any of the four ICT channels, namely mobile application, short message service (SMS), Unstructured Supplementary Service Data (USSD), and web application. On the other hand, the information user can retrieve information and upload feedback via any of the same channels. The fisheries stakeholders can play either of the two roles (information providers or information users) during system interaction.

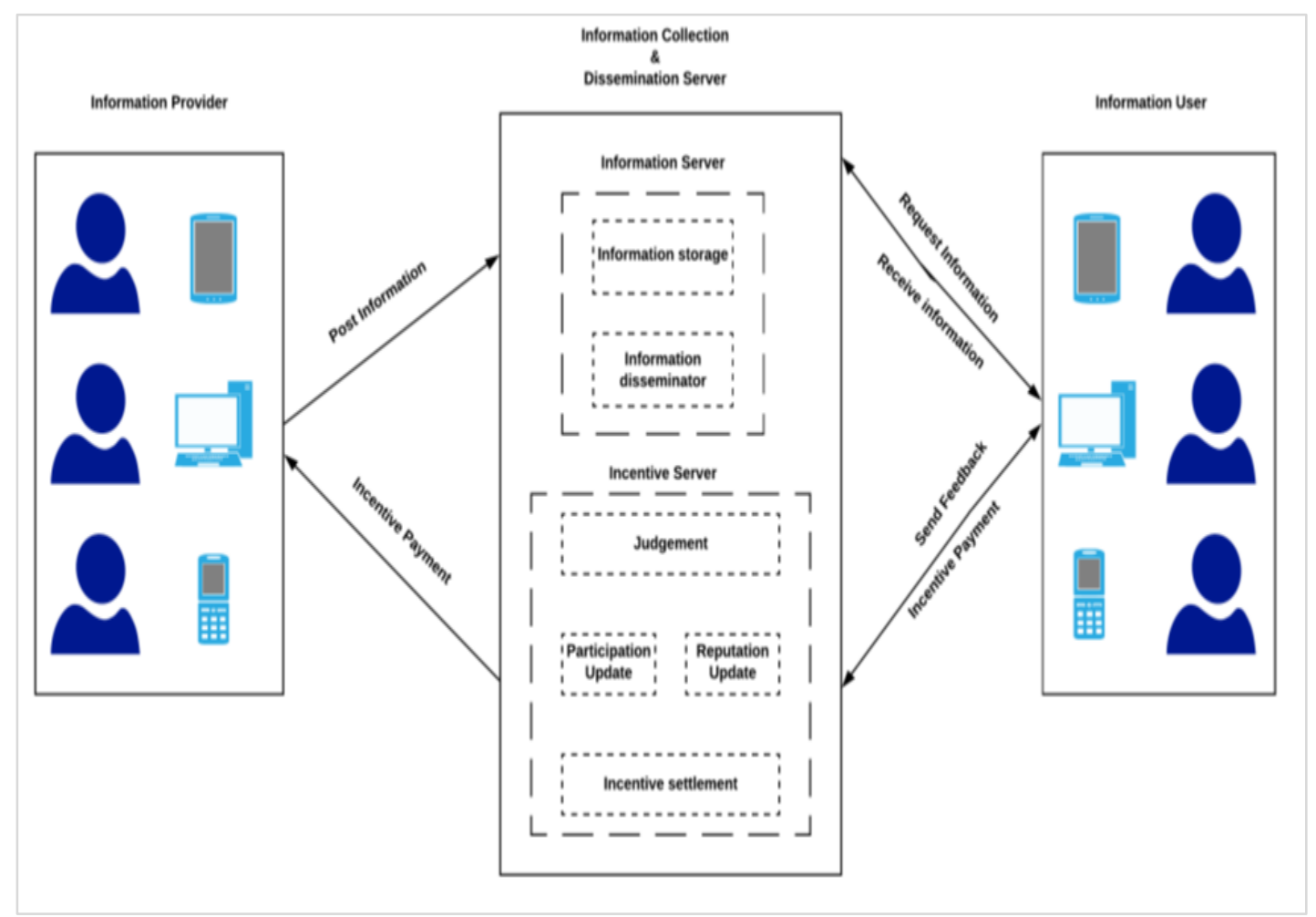

Figure 1 PRIGM system model

- Information providers are stakeholders who, at any time t, upload information to the information collection and dissemination server. They also receive incentives based on their participation and reputation for a given period specified.

- Information users are stakeholders who, at any time, retrieve information and upload feedback to the information collection and dissemination server. They also receive incentives based on their participation and reputation for a given period specified.

- The collection and dissemination server primarily consist of two system components: information server and incentive server. The information server is responsible for storing the uploaded information and dissemination of requested information to the users. The incentive server is responsible for participation, reputation, and incentive management during the entire system interaction.

The complete PRIGM system model works as follows:

- The information saver saves the data whenever a user uploads any information, and the incentive saver via participation component updates user participation accordingly.

- Whenever a user retrieves any information, the information saver disseminates the requested information, and the incentive saver via participation update component updates user participation accordingly. 
- The information saver saves the feedback information whenever a user uploads any feedback about retrieved information; the incentive saver via reputation update component updates information user reputation and the designated information uploader reputation.

- After a specified time, the model calculates user participation and reputation score, judge users honest and dishonest, calculates incentive and penalty, and lastly, disburse accordingly to respective users.

- Lastly, the model resets the user's participation and reputation scores, and the interaction circles continue.

\section{Modeling, coding, and simulation}

This study introduced a sigmoid function to compute the user's reputation and participation score, respectively. We used the sigmoid function because it returns a value ranging between zero and one. The sigmoid function is more appropriate than other functions for modeling the concept of human behavior and has been widely used [17]. Equation (1) defines the sigmoid function used in this study.

$$
f(\mathrm{x})=1-\frac{1}{1+\mathrm{x}}
$$

The system model has a number of players (users) denoted as $\mathrm{P}=\{\mathrm{p} 1, \mathrm{p} 2, \mathrm{p} 3, \mathrm{p} 4 \ldots \mathrm{pn}\}$. The strategy of each player (Users) corresponds to Participating Honestly (H) and Participating dishonestly (D). Thus, each player (User) will have the same set of two strategies, honest and dishonest, denoted as $\mathrm{S}=\{\mathrm{H}$, D\}. Table 1 defines all notations and symbols used by this model. The participation and reputation score was calculated by the function (2) and (3), denoted by $P i, t(z)$, and $R i, t(z)$, respectively.

$P i, t(z)=1-\frac{1}{1+z}$

The output $P i, t(z)$ of the equation (2) is the participation score of a given user and is a number in the range of zero and one. It represents a participation score for a particular user $P i$ at time t.

$R i, t(r)=1-\frac{1}{1+r}$

The output $R i, t(r)$ of the equation (3) is the reputation score of a given user ranging from zero and one. It represents a reputation score for a particular user $\mathrm{Pi}$ at time $t$.

Table 1 Definition of terms and notations

\begin{tabular}{ll}
\hline Symbol & Definition \\
\hline$P i, P j$ & Information providers and information users, respectively \\
\hline$I r$ & Incentive Score rate \\
\hline$P r$ & Penalty Score rate \\
\hline$R i, t$ & Users $P i$ reputation Score at time $t$ \\
\hline$R j, t$ & Users $P j$ reputation Score at time $t$ \\
\hline$U i, t(x, y)$ & $\begin{array}{l}\text { The Expected Utility for user } P i \text { at time } t \text { when the information provider takes action } x \text {, and information user } \\
\text { takes action } y\end{array}$ \\
\hline$U j, t(x, y)$ & $\begin{array}{l}\text { The Expected Utility for user } P j \text { at time } t \text { when the information provider takes action } x \text {, and information user } \\
\text { takes action } y\end{array}$ \\
\hline $\mathrm{z}$ & Number of times user upload information or retrieve information \\
\hline $\mathrm{r}$ & Number of useful information or truthful feedback user upload \\
\hline$P i, t$ & Users $P i$ participation score at time $t$ \\
\hline$P j, t$ & Users $P j$ participation score at time $t$ \\
\hline $\mathrm{A}$ & Incentive Score at time $t$ \\
\hline $\mathrm{K}$ & Penalty Score at time $t$ \\
\hline
\end{tabular}

For the model to judge the stakeholder's honesty or dishonesty we defined that, if $\left[\frac{R i, t}{1+P i, t}\right]>0$; then the stakeholder is honesty, and if $\left[\frac{R i, t}{1+P i, t}\right]=0$; then the stakeholder is dishonesty. To simplify the judgment, we denote $\mu$ to represent whether user $P i$ participates honestly or participating dishonestly at time t. We set $\mu$, as indicated in equation (4), to give incentives to honesty users and punish dishonest users accurately.

$$
\mu=\left\{\begin{array}{r}
1, \text { Pi is participating honestly } \\
-1, \text { Pi is participating dishonestly }
\end{array}\right.
$$

In our simulation experiment, we used equations 5 and 6 to calculate the incentive score denoted by $\mathbf{A}$ and the penalty score denoted by $\mathbf{K}$.

$$
A=\left[\frac{R i, t}{1+P i, t}\right] \times \mathrm{Ir}
$$


$K=\left[\frac{P i, t}{1+P i, t}\right] \times \operatorname{Pr}$

During the evolutionary game, the two players' information provider $\boldsymbol{P} \boldsymbol{i}$ and information user $\boldsymbol{P} \boldsymbol{j}$, are not entirely rational. Thus, the expected payoff of information provider $\boldsymbol{P i}$ in each strategy profile is defined as follows;

The $\boldsymbol{U}_{i, t}(\boldsymbol{H}, \boldsymbol{H})$ denotes the payoff for information provider $\boldsymbol{P} \boldsymbol{i}$ when both information users and information providers choose strategy honest $(\mathbf{H})$ during their system interaction at tome $t . \boldsymbol{U}_{i, t}(\boldsymbol{H}, \boldsymbol{D})$ denotes payoff for information provider $\boldsymbol{P} \boldsymbol{i}$ when the information user selects strategy dishonest (D). In contrast, the information provider selects strategy honest $(\mathbf{H})$ during their system interaction at time $\boldsymbol{t}$. $\boldsymbol{U}_{i, t}(\boldsymbol{D}, \boldsymbol{H})$ denotes the payoff for information provider $\boldsymbol{P} \boldsymbol{i}$ when the information user selects strategy Honest $(\mathbf{H})$, and the information provider selects strategy dishonest (D) during their system interaction a time $\boldsymbol{t}$. $\boldsymbol{U}_{i, t}(\boldsymbol{D}, \boldsymbol{D})$ denotes the payoff for information provider $\boldsymbol{P} \boldsymbol{i}$ when both information users and information providers select strategy dishonest (D) during their system interaction at time $t$. Table 2 summarizes these payoffs for information provider Pi.

The expected payoff of information user $\boldsymbol{P} \boldsymbol{j}$ in each strategy profile is defined as follows;

The $\boldsymbol{U}_{j, t}(\boldsymbol{H}, \boldsymbol{H})$ denotes the payoff for information user $\boldsymbol{P} \boldsymbol{j}$ when both information users and information providers choose strategy honest $(\mathbf{H})$ during system interaction at time $\boldsymbol{t} . \boldsymbol{U}_{j, t}(\boldsymbol{H}, \boldsymbol{D})$ denotes payoff for information user $\boldsymbol{P} \boldsymbol{j}$ when the information user selects strategy honest $(\mathbf{H})$, and the information provider selects strategy dishonest (D) during their system interaction at time $\boldsymbol{t} . \boldsymbol{U}_{j, t}(\boldsymbol{D}, \boldsymbol{H})$ denotes the payoff for information user $\boldsymbol{P} \boldsymbol{j}$ when the information user selects strategy dishonest (D), and the information provider decides strategy honest $(\mathbf{H})$ during their system interaction a time $\boldsymbol{t} . \quad \boldsymbol{U}_{j, t}(\boldsymbol{D}, \boldsymbol{D})$ denotes the payoff for information user $\boldsymbol{P} \boldsymbol{j}$ when both information user and information provider selects strategy dishonest (D) during their system interaction at time t. Table 3 summarizes these payoffs for information provider $\boldsymbol{P}$.

Users must be encouraged to participate honestly to guarantee the performance of the system model. The constraints denoted by equation (7) were defined within the system model to ensure that each user participate honestly;

$$
\left\{\begin{array}{l}
U i, t(\mathrm{H}, \mathrm{H})>U i, t(\mathrm{H}, \mathrm{D}) \\
U i, t(\mathrm{D}, \mathrm{H})>U i, t(D, D) \\
U j, t(\mathrm{H}, \mathrm{H})>U j, t(\mathrm{H}, \mathrm{D}) \\
U j, t(\mathrm{D}, \mathrm{H})>U j, t(\mathrm{D}, \mathrm{D})
\end{array}\right.
$$

The model updates the user's participation and reputation based on the user's strategy selection during each iteration after each play of the evolutionary game. After a specified period $t$, participation and reputation score are calculated for each user and used to judge the users' honesty or dishonesty accordingly. In the judgment model, $\boldsymbol{\mu}$ represents whether the user participates honestly or participating dishonestly at time $t$. Therefore, to pay incentives to honesty and punish dishonest users, $\boldsymbol{\mu}$ is set, as shown by equation (8). Thus, Table 4 shows the matrix of $\boldsymbol{\mu}$, which determines whether the user should be incentivized or punished.

$$
\mu=\left\{\begin{array}{r}
1, \text { Pi is participating honestly } \\
-1, \text { Pi is participating dishonestly }
\end{array}\right.
$$

Table 2 Payoff matrix of information providers $\mathrm{Pi}$

\begin{tabular}{llll}
\cline { 2 - 4 } Information Provider $\mathbf{P}_{\mathbf{i}}$ & \multicolumn{3}{c}{$\mathrm{H}$} \\
\cline { 2 - 4 } & $\mathrm{H}$ & $\mathrm{U}_{\mathrm{i}, \mathrm{t}}(\mathrm{H}, \mathrm{H})$ & $\mathrm{D}$ \\
\cline { 2 - 4 } & $\mathrm{D}$ & $\mathrm{U}_{\mathrm{i}, \mathrm{t}}(\mathrm{D}, \mathrm{H})$ & $\mathrm{U}_{\mathrm{i}, \mathrm{t}}(\mathrm{D}, \mathrm{D}, \mathrm{D})$ \\
\hline
\end{tabular}

Table 3 Payoff matrix of information users $\mathrm{Pj}$

\begin{tabular}{clll}
\hline \multirow{3}{*}{ Information user $\mathbf{P}_{\mathbf{j}}$} & \multicolumn{4}{c}{ Information provider } \\
\cline { 2 - 4 } & \multicolumn{4}{c}{$\mathrm{H}$} & $\mathrm{D}$ \\
\cline { 2 - 4 } & $\mathrm{H}$ & $\mathrm{U}_{\mathrm{j}, \mathrm{t}}(\mathrm{H}, \mathrm{H})$ & $\mathrm{U}_{\mathrm{j}, \mathrm{t}}(\mathrm{H}, \mathrm{D})$ \\
\hline
\end{tabular}


Table 4 Matrix of $\mu$

\begin{tabular}{lccc}
\hline & \multicolumn{3}{c}{ Information users Pj } \\
\cline { 2 - 4 } Information Provider $\mathbf{P}_{\mathbf{i}}$ & \multicolumn{3}{c}{$\mathrm{H}$} \\
\cline { 2 - 4 } & $\mathrm{H}$ & $(1,1)$ & $\mathrm{D}$ \\
\cline { 2 - 4 } & $\mathrm{D}$ & $(-1,1)$ & $(1,-1)$ \\
\hline
\end{tabular}

Equation (9) and (10) describe each player's expected incentive in the strategy profile where both information providers and information users are honest at time $\boldsymbol{t}$, respectively.

$$
\begin{aligned}
& \left\{\begin{array}{l}
U i, t(\mathrm{H}, \mathrm{H})=\left[\frac{R i, t}{1+P i, t}\right] \times \mathrm{Ir} \\
\left\{U j, t(\mathrm{H}, \mathrm{H})=\left[\frac{R j, t}{1+P j, t}\right] \times \mathrm{Ir}\right.
\end{array}\right.
\end{aligned}
$$

The expected incentive or penalty to each player in the strategy profile where information providers are honest, and information users are dishonest at time $\mathrm{t}$ described by equation (11) and (12).

$$
\begin{gathered}
\left\{U i, t(\mathrm{H}, \mathrm{D})=\left[\frac{R i, t}{1+P i, t}\right] \times \operatorname{Ir}\right. \\
\left\{U j, t(\mathrm{H}, \mathrm{D})=\left[\frac{P j, t}{1+P j, t}\right] \times \operatorname{Pr}\right.
\end{gathered}
$$

The expected incentive or penalty to each player in the strategy profile where information providers are dishonest, and information users are honest at time $\mathrm{t}$ described by equation (13) and (14).

$$
\begin{aligned}
& \left\{\begin{array}{l}
U i, t(\mathrm{D}, \mathrm{H})=\left[\frac{P i, t}{1+P i, t}\right] \times \operatorname{Pr} \\
\left\{U j, t(\mathrm{D}, \mathrm{H})=\left[\frac{R j, t}{1+P j, t}\right] \times \mathrm{Ir}\right.
\end{array}\right.
\end{aligned}
$$

Equation (15) and (16) describe the expected penalty to each player in the strategy profile where both information providers and information users are dishonest at time $\boldsymbol{t}$ respectively.

$$
\begin{aligned}
& \left\{\begin{array}{l}
U i, t(\mathrm{H}, \mathrm{H})=\left[\frac{P i, t}{1+P i, t}\right] \times \operatorname{Pr} \\
\left\{U j, t(\mathrm{H}, \mathrm{H})=\left[\frac{P j, t}{1+P j, t}\right] \times \operatorname{Pr}\right.
\end{array}\right.
\end{aligned}
$$

We modeled the stakeholder's participation as an evolutionary game and coded the model using the python programming language. We selected Python programming language because it has many useful libraries, powerful for computation simulations. We simulated the model in five cases, each with four- game rounds plays, using different stakeholder participants in each case. Lastly, we used a bar chart graph to evaluate the stakeholder's honest and dishonest behavior in four rounds for each stakeholder participant.

\section{Simulation results and discussion}

We present the simulation results for our proposed PRIGM mechanism assuming the incentive ratio (Ir) and penalty ratio (Pr) as 0.5 unit. We kept this ratio the same for all experiment cases. We simulated the model in 5 cases with 50, 500, 1000, 2000, and 5000 stakeholders. The simulation generates stakeholders' names, roles, participation ( $\mathrm{z}$ ), and reputation (r) randomly on every iteration case. In both cases, we assumed that the learning ratio for participating stakeholders to be 0.2. Each iteration case represents all possible simultaneous interactions between the stakeholders.

\section{The case I: 50 stakeholders}

We simulated our model with 50 stakeholders; plot the number of honest and dishonest stakeholders against each game's number, as shown in Figure 2. We observed that during the first round, 15 stakeholders were honest, and 35 stakeholders were dishonest. The second round,20 stakeholders, are honest, and 30 stakeholders are dishonest. In the third round, 25 stakeholders are honest, and 25 stakeholders are dishonest. The fourth round, 35 stakeholders, are honest, and 15 stakeholders are dishonest. Results show an increase in the number of stakeholders scoring incentives and a decrease of stakeholders scoring a penalty on every game. Our result depicts that stakeholders learn from received payoff for every strategy chosen during a game round and change strategy to maximize their payoffs.

\section{Case II: 500 Stakeholders}

Simulating the model with 500 stakeholders, we observed that, during the first round, 195 stakeholders were honest, and 305 stakeholders were dishonest. The second round, 250 stakeholders are honest, and 250 stakeholders are dishonest; third round, 300 stakeholders are honest, and 200 stakeholders are dishonest. In the fourth round, 380 stakeholders are honest, and 120 stakeholders are dishonest. Figure 3 depicts these results, showing an increase in the number of stakeholders scoring 
incentives and decreasing the stakeholder's scoring penalty on every game round. This result indicates that stakeholders continue learning from received payoff for every strategy chosen during a game round and change strategy to maximize their payoffs.

\section{Case III: 1000 Stakeholders}

When simulating the model with 1000 stakeholders, we observed that during the first game round, 390 stakeholders were honest, and 610 stakeholders were dishonest. The second game round, about 450 stakeholders, are honest, and 550 stakeholders are dishonest. During the third game round, 610 stakeholders are honest, and 390 stakeholders are dishonest. In the fourth game round, about 800 stakeholders are honest, and 200 stakeholders are dishonest. Figure 4 depicts these results, showing an increase in the number of stakeholders scoring incentives and decreasing the stakeholder's scoring penalty on every game round. This result also indicates that stakeholders continue learning from received payoff for every strategy chosen during a game round and change strategy to maximize their payoffs.

\section{Case IV: 2000 Stakeholders}

We then simulated the model with 2000 stakeholders, and the result shows that for the first game, around 800 stakeholders were honest, and 1200 stakeholders were dishonest. In the second game round, about 1000 stakeholders are honest, and 1000 stakeholders are dishonest. More than 1200 stakeholders are honest during the third game to round, and around 800 stakeholders are dishonest. In the fourth game round, about 1550 stakeholders are honest, and 450 stakeholders are dishonest. Figure 5 depicts these results, showing an increase in the number of stakeholders scoring incentive and decreasing the stakeholder's scoring penalty on every game round.
This result also indicates that stakeholders continue learning from received payoff for every strategy chosen during a game round and change strategy to maximize their payoffs. As time goes on during the evolutionary game, more participating stakeholders' select an honest strategy.

Case V: 5000 Stakeholders

Lastly, we simulated the model with 5000 stakeholders, and the result shows that for the first game, around 200 stakeholders were honest, and more than 3000 stakeholders were dishonest. In the second game round, about 2300 stakeholders are honest, and 2700 stakeholders are dishonest. During the third game round, about 3000 stakeholders are honest, and around 2000 stakeholders are dishonest. In the last game round, about 3800 stakeholders are honest, and 1200 stakeholders are dishonest. Figure 6 depicts these results, showing an increase in the number of stakeholders scoring incentives and decreasing the stakeholder's scoring penalty on every game round. This result also indicates that stakeholders continue learning from received payoff for every dishonest strategy chosen during a game round, change strategy to honest, and maximize their payoffs. As time goes on during the evolutionary game, more participating stakeholders' select an honest strategy.

The comparative analysis of the simulation results in all five cases shows that no matter of the population of stakeholders or a high number of stakeholders choosing dishonest strategy at the beginning of the game, after several game rounds, the majority of stakeholders will be motivated to choose an honest strategy.

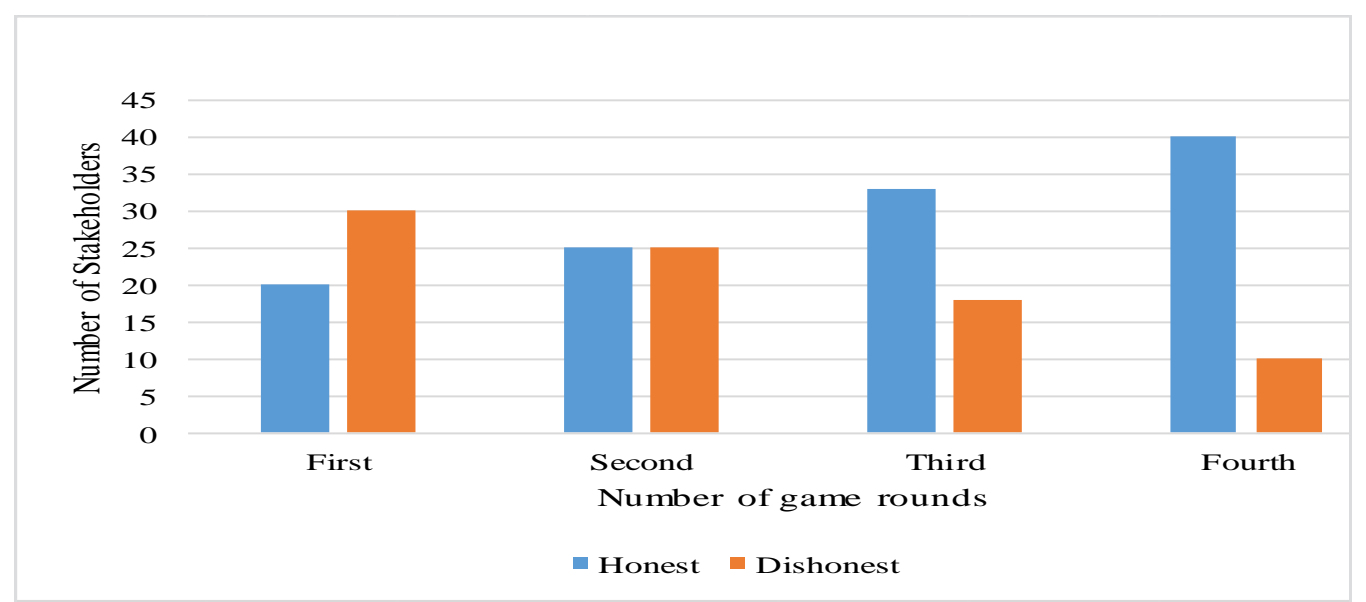

Figure 2 Case I distribution of stakeholders by strategies and game rounds 
Sadiki Lameck Kusyama et al.

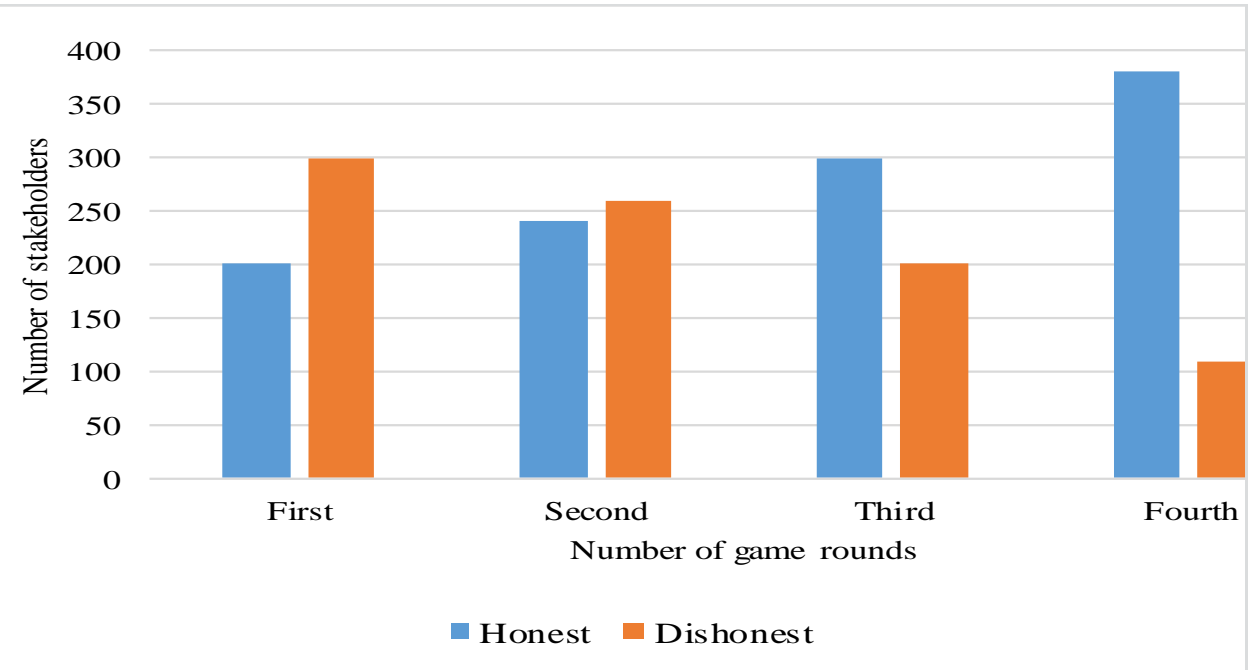

Figure 3 Case II distribution of stakeholders by strategies and game rounds

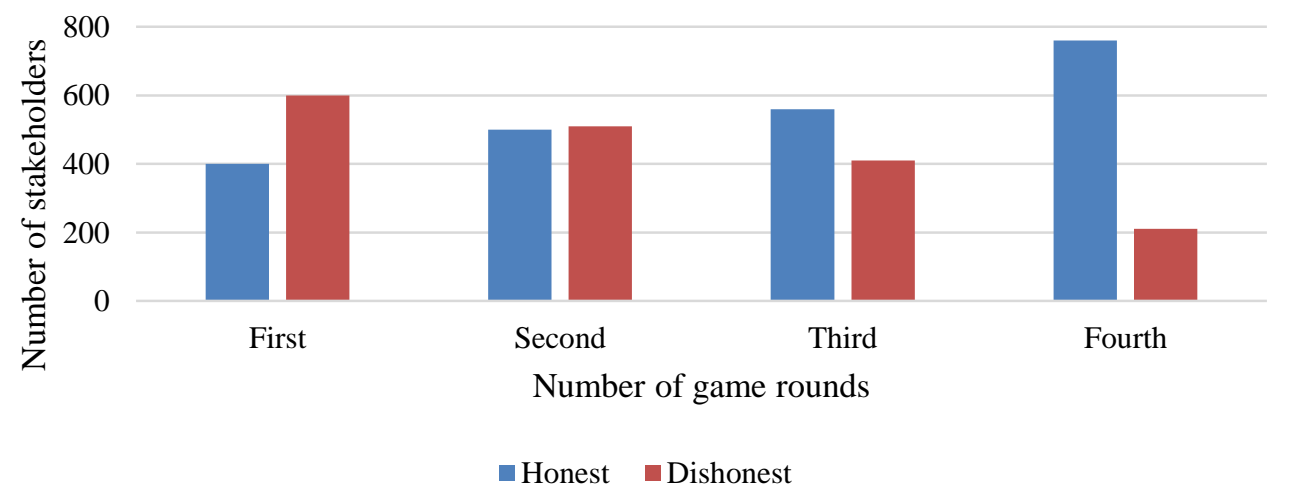

Figure 4 Case III distribution of stakeholders by strategies and game rounds

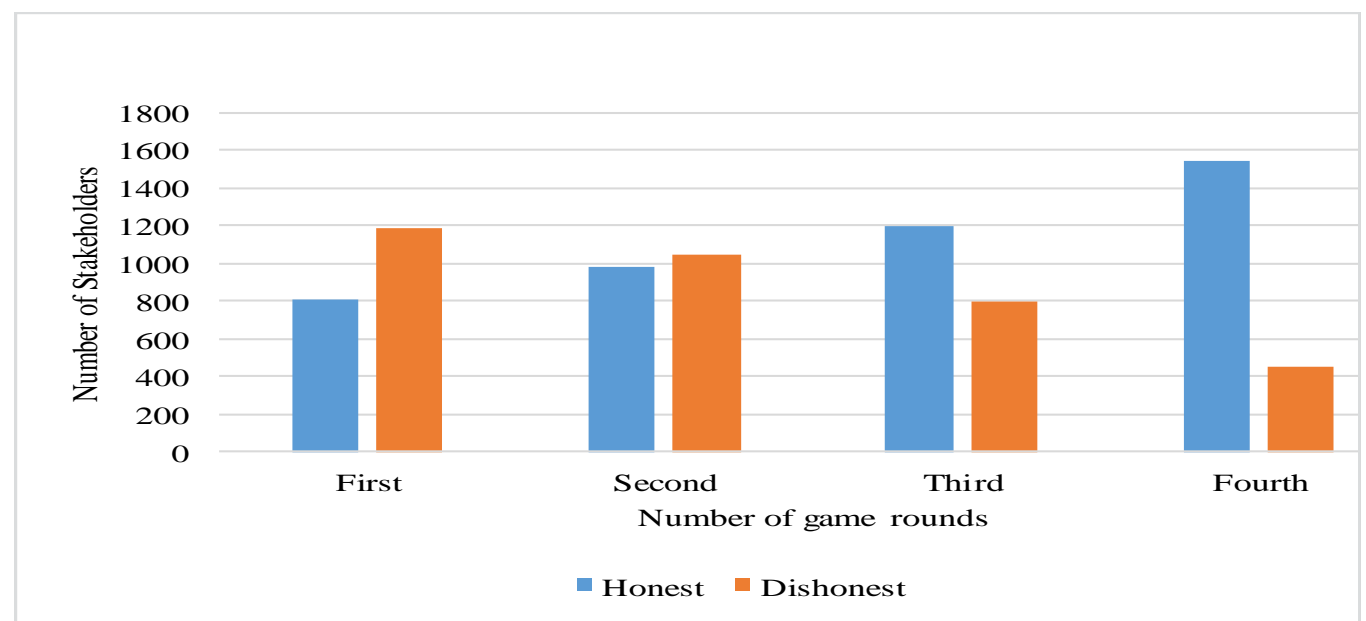

Figure 5 Case IV distribution of stakeholders by strategies and game rounds 


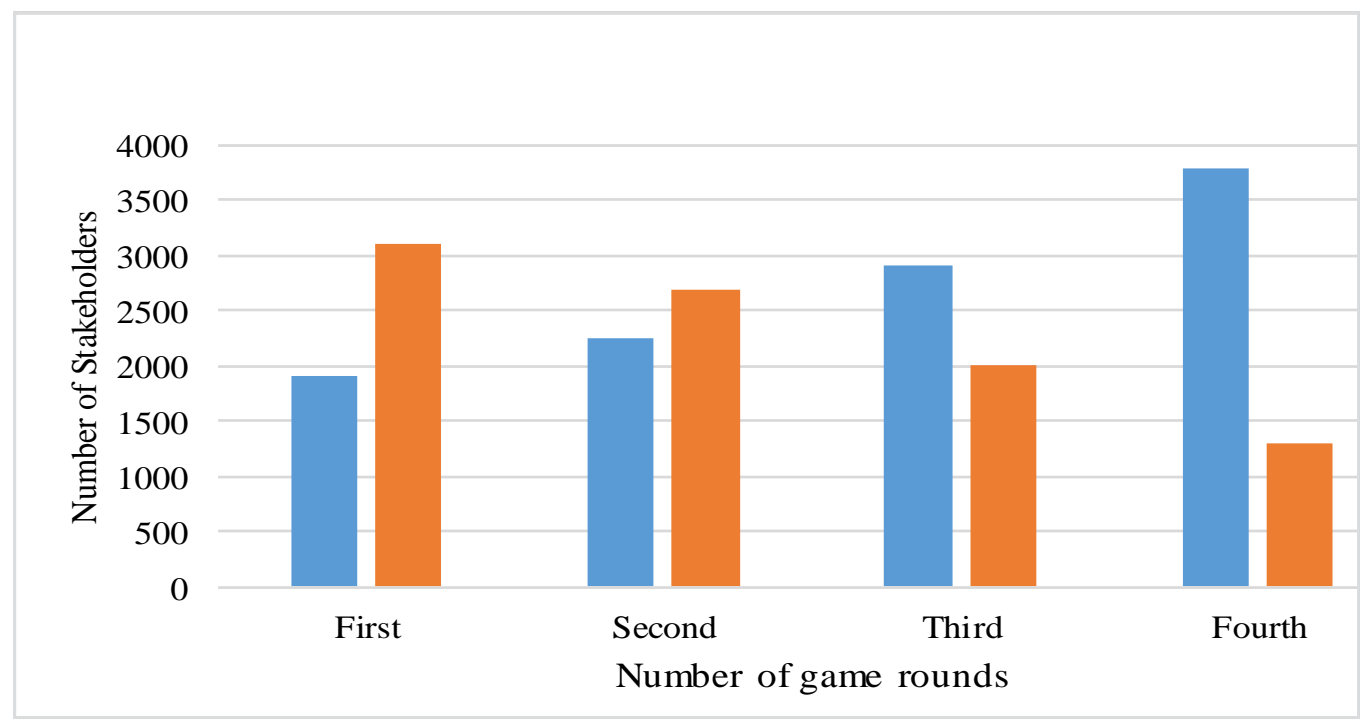

Figure 6 Case V distributions of stakeholders by strategies and game rounds

\section{Conclusion and recommendation}

The dishonest behavior of human beings seriously threatens the adoption and performance of fisheries information collection and dissemination. In this research work, we have proposed PRIGM, which employed a participation-reputation based incentive game model to motivate fisheries stakeholders to make use, contribute accurate information, and submit truthful feedbacks to the system. We simulated the non-cooperative evolutionary process of the fisheries stakeholder interactions. The results proved that PRIGM effectively motivates stakeholders to use the system, contribute accurate information, and submit truthful feedback.

With slight changes depending on the nature of the system, PRIGM can be used in other systems to solve human users' dishonest behavior. Future work will research evolutionary game in more complicated systems of other sectors and propose appropriate incentive mechanism.

\section{Acknowledgment}

None.

\section{Conflicts of interest}

The authors have no conflicts of interest to declare.

\section{References}

[1] Salam SA, Arman ZR. Uses of information and communication technologies in fishery sector: a study on the fisherfolks of the utubdia island of Bangladesh. ICT for Development Working Paper Series. 2013.

[2] Akinbile LA, Alabi OE. Use of ICTs among fish farmers in Oyo State. Journal of Agricultural Extension. 2010; 14(1):22-30.
[3] Mtega WP, Benard R. The state of rural information and communication services in Tanzania: a metaanalysis. International Journal of Information and Communication Technology Research. 2013; 3(2):6473.

[4] Ogboma MU. Access to agricultural information by fish farmers in Niger Delta region of Nigeria. Journal of Library Philosophy and Practice. 2010.

[5] Annune AE, Ezeani CN, Okafor VN. Information sources dissemination and utilization patterns of the artisanal fishery sector in Benue state, Nigeria. Advances in Research. 2014; 2(12):889-905.

[6] Benard R, Dulle FW. Application of ICT tools in communicating information and knowledge to artisanal fishermen communities in Zanzibar. Knowledge Management \& E-Learning. 2017; 9(2):239-53.

[7] Qureshi B, Pathan M, Chandio FA, Keerio A, Buriro RA, Chhachhar AR. Adoption of information communication technology tools among fishermen. Journal of American Science. 2014; 10(7):155-61.

[8] https://www.auibar.org/component/jdownloads/viewdownload/5gi/1958-gi-20140905-pan-african-fisheries-datacollection-strategy-en. Accessed 28 March 2020.

[9] Petrik M, Serge Raemakers D. The case for supporting small-scale fisheries governance through ICT. South African Institute of International Affairs. 2018.

[10] Mallalieu KI. Rejuvenating ACP smallscale fisheries using ICTs. CTA. 2015.

[11] Van Schalkwyk F, Young A, Verhulst S. Esoko: leveling the information playing field for smallholder farmers in Ghana. ODI (Open Data's Impact). 2017.

[12] Wulandari S, Rahmah M. A survey on crowdsourcing awareness in Indonesia micro small medium enterprises. In IOP conference series: materials science and engineering 2020 (p.1-8). IOP Publishing. 
[13] Zhang X, Yang Z, Sun W, Liu Y, Tang S, et al. Incentives for mobile crowd sensing: a survey. IEEE Communications Surveys \& Tutorials. 2015; 18(1):5467.

[14] Zhang X, Yang Z, Zhou Z, Cai H, Chen L, Li X. Free market of crowdsourcing: incentive mechanism design for mobile sensing. IEEE Transactions on Parallel and Distributed Systems. 2014; 25(12):3190-200.

[15] Zhang Q, Wen Y, Tian X, Gan X, Wang X. Incentivize crowd labeling under budget constraint. In IEEE conference on computer communications 2015 (pp. 2812-20). IEEE.

[16] Wen Y, Shi J, Zhang Q, Tian X, Huang Z, Yu H, et al. Quality-driven auction-based incentive mechanism for mobile crowd sensing. IEEE Transactions on Vehicular Technology. 2014; 64(9):4203-14.

[17] Ma X, Ma J, Li H, Jiang Q, Gao S. RTRC: a reputation-based incentive game model for trustworthy crowdsourcing service. China Communications. 2016; 13(12):199-215.

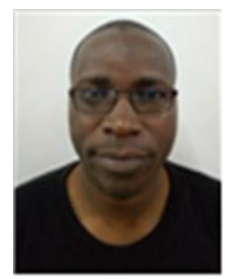

Sadiki Lameck Kusyama, received a Bachelor degree in Computer Engineering in 2009 from Dar es Salaam Institute of Technology (DIT), Masters in Information and Communication Science and Engineering in 2014 from Nelson Mandela African Institution of Science and Technology (NM-AIST). Currently he is doing $\mathrm{PhD}$ in Information and Communication Science and Engineering, Specializing in Information Technology Systems Development and Management (ITSDM) at NM-AIST, Arusha, Tanzania. His current research interests are ICT4D, Machine Learning, Big data analysis and Artificial Intelligence.

Email: sadikil@nm-aist.ac.tz

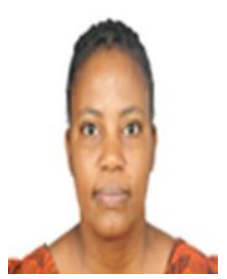

Dina Machuve is a Lecturer at the Nelson Mandela African Institute of Science and Technology (NM-AIST) in Tanzania. She holds a $\mathrm{PhD}$ in Information and Communication Science and Engineering from NMAIST (2016), MSc in Electrical Engineering from Tennessee Technological University, USA (2008), and BSc in Electrical Engineering from the University of Dar es Salaam (2001). Her research interests are Data Science and Agriculture Informatics.

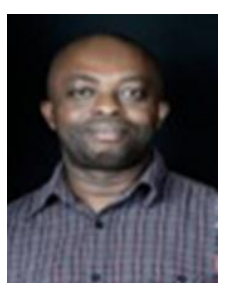

Kisangiri F. Michael has been working with NM-AIST as lecturer then Senior lecturer since December 2011. Before joining NM-AIST, he worked with Dar-es Salaam Institute of Technology in the position of lecturer for 3 years. $\mathrm{He}$ is a $\mathrm{PhD}$ holder in the field of Telecommunications, with which he graduated from Wroclaw University of Technology-Poland. currently he is working as academician and has supervised dozens of MSc and several Phd researches. He possesses good knowledge in Artificial intelligence, Antenna design, and wireless communication systems. He is fluent speaker of three languages: Swahili, English, Polish.

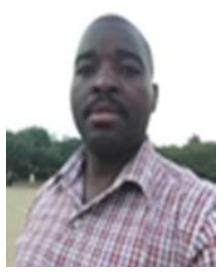

Dr. Abswaidi Ramadhani received a Bachelor in Computer Science in 2009, Masters in Information and Communication Science and Engineering in 2013 and a $\mathrm{PhD}$ in Information and Communication Science and Engineering in 2017 from Nelson Mandela African Institution of Science and Technology (NM-AIST). He has been involving in teaching Computer Science courses, carrying research and providing consultancy services related to his area of expertise and interest. He saved as a tutor at Mbeya Institute of Science and Technology (MIST) before joining Moshi Co-operative University. His current research interests are ICT4D and IOT. 